Research Article

\title{
Optimization Design and Internal Flow Field Study of Open-Design Vortex Pump
}

\author{
Xiongfa Gao $\left(\mathbb{D},{ }^{1}\right.$ Weidong Shi $\mathbb{D},{ }^{2}$ Ruijie Zhao, ${ }^{1}$ Ting Zhao, ${ }^{1}$ and Hongfei Wang ${ }^{3}$ \\ ${ }^{1}$ National Research Center of Pumps, Jiangsu University, Zhenjiang 212013, China \\ ${ }^{2}$ School of Mechanical Engineering, Nantong University, Nantong 226000, China \\ ${ }^{3}$ Shanghai Kaiquan Pump (Group) Co., Ltd., Shanghai 201804, China \\ Correspondence should be addressed to Xiongfa Gao; gxfyq@ujs.edu.cn and Weidong Shi; wdshi@ujs.edu.cn
}

Received 25 October 2020; Revised 12 November 2020; Accepted 4 March 2021; Published 18 March 2021

Academic Editor: Peter Mucka

Copyright ( $\odot 2021$ Xiongfa Gao et al. This is an open access article distributed under the Creative Commons Attribution License, which permits unrestricted use, distribution, and reproduction in any medium, provided the original work is properly cited.

To determine the influences of the main structural parameters on open-design vortex pump performance, optimize the vortex pump performance, and reduce the running vibration and improve stability, orthogonal testing method was introduced in this paper. The selected main factors included impeller outer diameter $\left(D_{2}\right)$, impeller outlet width $\left(b_{2}\right)$, outlet setting angle of impeller $\left(\beta_{2}\right)$, and inlet setting angle of impeller $\left(\beta_{1}\right)$, and the nine types of impellers were coded according to orthogonal table. After obtaining the preliminarily optimum value range for each factor through range analysis, comprehensive analysis was employed based on the orthogonal test to investigate the main factors and identify the primary and secondary influencing factors affecting the performance of the vortex pump. An optimization scheme was obtained for further design. The results show that the numerical calculation results of the optimization scheme pump are in good agreement with the test results, and it shows the feasibility of the numerical calculation method. The testing results showed that efficiency and head of the optimal model were $4.2 \%$ and $9 \mathrm{~m}$ higher than those of the prototype model, respectively. Improved efficiency and head met the design requirements. The orthogonal testing method proved the feasibility of performance optimization of the vortex pump. The backflow occurs at the pump entrance and rotates in the same direction with impeller. It moves along the pipe wall from the lateral cavity to the inlet and encourters with the approaching flow.

\section{Introduction}

The production and application of vortex pump are relatively late, and the continuous in-depth research and the improvement of its structure are gradually applied to the sewage pumping of domestic sewage treatment and aquaculture industry, as well as the pulp pumping of light chemical industry. However, this equipment exhibits disadvantages, which include low efficiency and high energy consumption $[1,2]$. At present, there are few researches on the vortex pump. A new flow model was proposed by Schivley and Dussourd [3] to study the internal flow field of vortex pumps and pointed out that fluids can be sucked into pumps under the effects of atmospheric pressure when the static pressure is negative at the central region of the vortex. Chen [4] established the apparatus first for measuring the velocity distribution on the axial vertical profile in the vortex pump impeller and pressure distribution on the blade surface. The measuring methods are explained in more detail, and the measured results are presented. Quan et al. [5] aimed at the problem of whole efficiency decline caused by the internal flow structure of the vortex pump and took a certain type of vortex pump as the research object, and six groups of forward-curved and backward-curved blades were designed as the control group. It was found that, for the efficiency of the vortex pump, the efficiency of forwardcurved impeller was higher than that of backward-curved impeller before the design flow point, and after the design flow point, the efficiency of backward-curved impeller was higher than that of forward-curved impeller. Sha et al. [6] used rapeseed as solid particles and done experimental studies under different solid volume fractions and obtained 
the external characteristic curve of clean water and different solid-phase volume fractions, and the basic principles and characteristics of the solid-liquid two-phase flow of the vortex pump are further analyzed. A comprehensive analysis of the qualitative causal relationship between the change of the external characteristics of the pump and the internal flow field and the improvement measures for the optimal design of the vortex pump are proposed. In order to develop an understanding of the flow conditions and maximize the efficiency and minimize the cavitation occurrence of vortex pumps, numerical and experimental investigations have been carried out by Alexander Steinmann [7]. The cavitation behavior was estimated using the volume-of-fluid RayleighPlesset cavitation model. CFD results turned out to be appropriate to capture the qualitative flow conditions and therefore increase the knowledge about vortex pumps. Beyond that, the CFD results are not fully sufficient to calculate the quantitative values with required accuracy.

Peng et al. [8] used the particle model to study the wear of slurry pump under the condition of biased design. The results showed that the interface between the sheath and rotor near the tongue had a serious local wear under the condition of small flow. By removing the front and rear back blades, the wear degree at the junction can be effectively reduced, but the wear of the inner side of the front guard board will be intensified. Wang et al. [9] studied the effect of different turbulence models on the sound field of the pump. The results show that RNG K $\varepsilon \mathcal{E}$ model is the best one for the multistage centrifugal pump with vaned diffuser. In order to research the internal sound field characteristics and reduce the running noise of selfpriming vortex pump at a low flow rate, Wang et al. [10] adopted the CFD + Lighthill sound analogy theory to solve the internal acoustic field and optimize the noise of pump. The results showed that, with the decrease of the flow rate, the SPL of the pump discharge was increased, and the sound source of the self-priming vortex pump was mainly distributed in the channel and the tongue close to the pump discharge. Liu et al. [11] obtained the influence of the special volute structure of the vortex self-priming pump on its self-priming performance through 2D PIV and numerical simulation. The results show that the combination of the guide wall and the impeller outlet promotes the gas-water mixing and the formation of bubble flow and improves the self-priming performance.

At present, the research on this kind of vortex pump with special structure is scarce. The selection of main structural parameters of impeller, especially, is crucial for the performance of the vortex pump. This article took a typical open design vortex pump as the research object. Its optimization design was based on the orthogonal method, and the experimental verification is carried out. The optimal scheme of the vortex pump is further analyzed by the numerical simulation and the flow field is obtained, which also provided a reference for the design of the impeller.

\section{Orthogonal Test}

2.1. Pump Parameters. An open design vortex pump with a specific speed of 166 was selected as the research object. The design flow rate was $Q_{\mathrm{des}}=500 \mathrm{~m}^{3} / \mathrm{h}$; rated speed $n=1485 \mathrm{r} /$ min. The main structural parameters are shown in Table 1. At the rated point, experimental efficiency is $42.36 \%$, and the experimental head measures $20.24 \mathrm{~m}$; these values do not satisfy the specified efficiency and head values. Figure 1 shows the open-design vortex pump two-dimensional (2D) assembly [2].

\subsection{Numerical Calculation Methods}

2.2.1. Calculation Model. The calculation model of vortex pump was created based on the original model pump. The whole flow domain of the CFD model consists of five components, namely, inlet section, lateral cavity, impeller, volute, and outlet section. The original model pump calculation domains are shown in Figure 2 [2].

2.2.2. Mesh Sensitivity Analysis. The entire mesh of the pump generation was carried out in ICEM 13.0 software, as shown in Figure 2. In theory, with the increase in grid element number, errors caused by the grid will reduce gradually until they disappear [12-14]. However, considering computer configuration and computer time, the number of grid elements cannot be too large [15-17].

Table 2 shows results of grid sensitivity analysis. When grid sizes measure less than 5.0 and grid numbers are larger than $1.38 \times 10^{6}$, efficiency and head only experience slight changes, indicating the stability of simulation results. Considering computer calculation capabilities, the grid size of 4.5 was used to carry out the following experiments (as shown in Figure 3). In this paper, the value of $y+$ of the whole calculation model is lower than $50[18,19]$.

2.2.3. Boundary Condition. The CFD flow domain is divided into two types of subdomains: the first type of subdomain is the impeller, which is attached to the rotating frame and solved in a rotating framework via the multiple reference frame (MRF), and the rotational speed was set as $1485 \mathrm{r} / \mathrm{min}$. Other fluid domains, except the impeller, are the second type of subdomain, which is solved in a stationary framework $[20,21]$. The boundary conditions of the whole domain are shown in the Table 3 .

2.2.4. Turbulence Model. In general, the selection of turbulence model is empirical in numerical simulation of hydraulic rotating machinery, and it is not clear which turbulence model calculation results of the vortex pump are more accurate. Therefore, in order to find a more accurate turbulence model to calculate the vortex pump, in this paper, five turbulence models are selected to simulate the vortex pump in the design condition and carefully validate it by comparing the numerical simulation results with the experimental data.

The five turbulence models are the standard $k-\varepsilon$ model, RNG $k-\varepsilon$ model, realizable $k-\varepsilon$ model, standard $k-\omega$ model, and SST $k-\omega$ model. The numerical simulation results were compared with the experimental results with different turbulence models as shown in Table 4. On the whole, the 
TABle 1: Parameters of impeller and volute.

\begin{tabular}{lccc}
\hline impeller inlet diameter $\left(D_{1}\right)$ & $140 \mathrm{~mm}$ & Impeller outlet diameter $\left(D_{2}\right)$ & $350 \mathrm{~mm}$ \\
Blade wrap angle of impeller $(\theta)$ & $35^{\circ}$ & Impeller outlet width $\left(b_{2}\right)$ & $60 \mathrm{~mm}$ \\
Inlet setting angle of impeller $\left(\beta_{1}\right)$ & $40^{\circ}$ & Outlet setting angle of impeller $\left(\beta_{2}\right)$ & $35^{\circ}$ \\
Blade number of impeller $(z)$ & 10 & Lateral cavity width $(L)$ & $50 \mathrm{~mm}$ \\
Volute inlet diameter $\left(D_{3}\right)$ & $430 \mathrm{~mm}$ & Volute inlet width $\left(b_{3}\right)$ & $110 \mathrm{~mm}$ \\
\hline
\end{tabular}

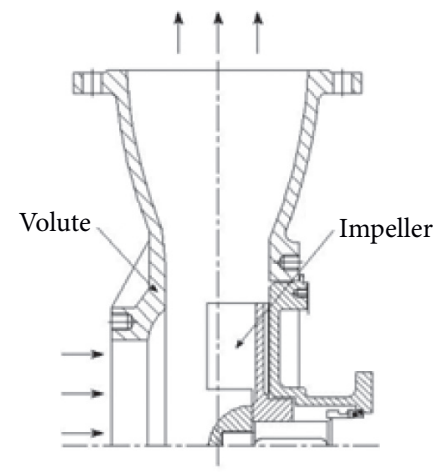

Figure 1: Simple diagram of pump section model.

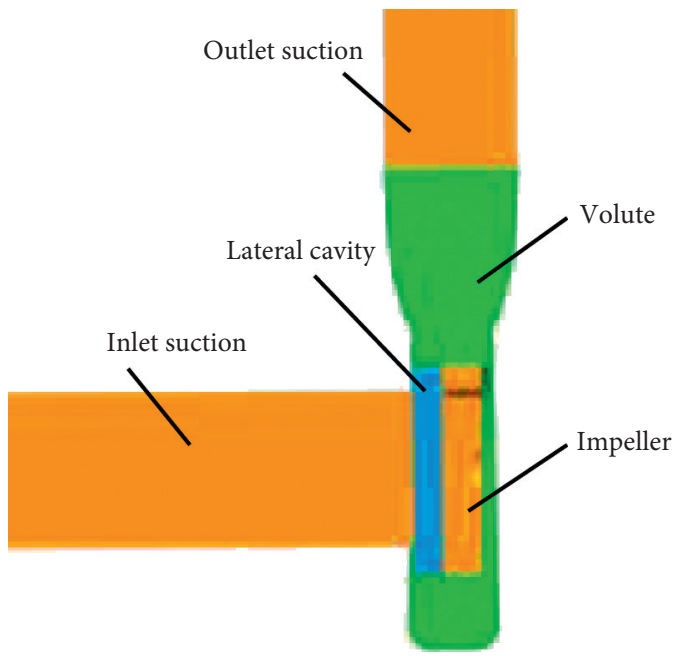

Figure 2: Calculation domains.

TABLE 2: Mesh independent analysis.

\begin{tabular}{lcccc}
\hline Mesh software & \multicolumn{4}{c}{ ICEM } \\
\hline Grid size & 4.5 & 5.0 & 5.5 & 6.0 \\
Grid elements & 1636421 & 1383790 & 986575 & 733659 \\
Efficiency $\eta(\%)$ & 46.342 & 46.339 & 45.725 & 45.236 \\
$H(\mathrm{~m})$ & 23.541 & 23.536 & 23.203 & 22.924 \\
\hline
\end{tabular}

SST $k-\omega$ and RNG $k-\varepsilon$ models predict the highest efficiency and head of vortex pump, and standard $k-\varepsilon$ model has the lowest and most close predicted value. Thus, the standard $k-\varepsilon$ model is chosen for the following numerical calculation.

2.2.5. Numerical Algorithm and Other Parameters. The numerical simulation of vortex pump is carried out by ANSYS-CFX 13.0, and the finite volume method is used to solve the Reynolds-averaged Navier-Stokes equations.
Second-order upwind discretization was used for the convective and diffusive terms, and the second-order upwind format is selected. SIMPLEC algorithm is selected to calculate the pressure-velocity coupling [22-25], and the convergence precision was set to $10^{-5}$.

2.3. Factors and Experimental Scheme. Vortex pump features a simple structure, but its internal flow is complex. Structural parameters are as follows: impeller diameter $\left(D_{2}\right)$, inlet diameter $\left(D_{j}\right)$, number of blades $(Z)$, blade width $(b)$, lateral cavity width $(L)$, blade outlet angle $\left(\beta_{2}\right)$, blade inlet angle $\left(\beta_{1}\right)$, and volute inlet diameter $\left(D_{3}\right)$.

In this paper, structural parameters of studied pump impeller are as follows: $D_{2}=340 \mathrm{~mm}, Z=10, b=60 \mathrm{~mm}$, $L=50 \mathrm{~mm}, \beta_{2}=35^{\circ}$, and $\beta_{1}=40^{\circ}$. The impeller was completely exposed to the cavity, and the impeller has no front cover, as shown in Figure 1. Changing the blade width $b$ is equivalent to changing the lateral cavity width $L$. The area of the impeller passage decreases with the increase of blade number, and the impeller passage is more easily plugged. Efficiency and head do not meet the predetermined values when blade number decreases. Therefore, the number of blades $(Z)$ was not considered and was kept constant. $D_{2}, b$, $\beta_{2}$, and $\beta_{1}$ were selected as the orthogonal experimental factors in this study. Factor levels are shown in Table 5. Nine kinds of impeller structure parameters were selected based on the standard orthogonal table [26], as indicated in Table 4 $\left(D_{2}, b, \beta_{2}\right.$, and $\beta_{1}$ are represented by $\mathrm{A}, \mathrm{B}, \mathrm{C}$, and $\mathrm{D}$, respectively). The hydraulic design of impeller was obtained by the structural parameters of each impeller. In rated flow, efficiency and head values of the nine sets of programs were obtained based on CFD, as shown in Table 6 .

\section{Orthogonal Results and Flow Field Analysis}

3.1. Orthogonal Test Analysis. At rated flow condition, efficiency and head values of the nine sets of schemes were obtained through CFD, as shown in Table 4. Efficiency and head are the most important pump indicators. Therefore, efficiency and head are selected as evaluation indexes.

The two evaluated indexes in this research belong to multi-index orthogonal experiment. Intuitive analysis of overall balance method was used to determine the main factor and optimization program. Visual analysis for each indicator was carried out, and the results were studied by comprehensive comparative analysis.

Table 7 shows the results of range analysis, with each column representing a different range. The values reflect the influence level of indicators, which affects the factor level in turn. A large range indicates large influence of indicator on the factor level selection. Therefore, factors with the largest 


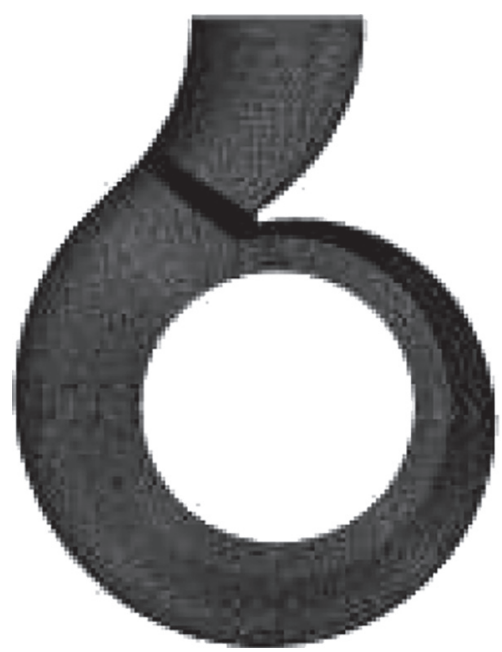

(a)

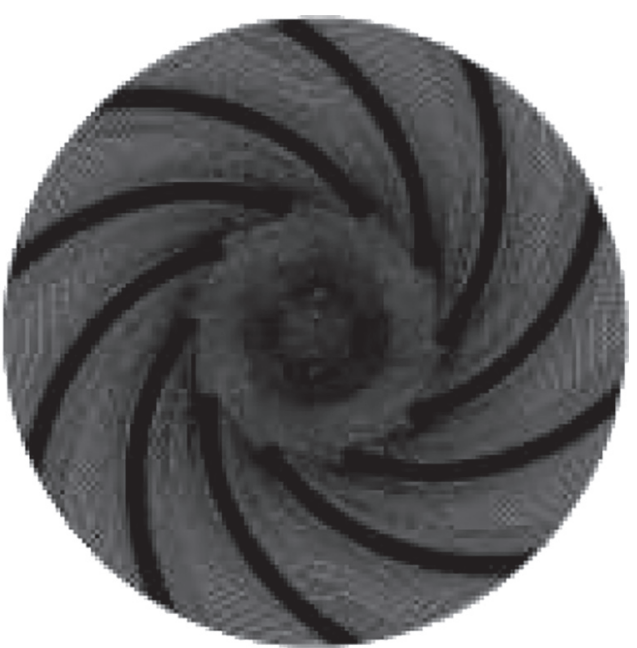

(b)

FIGURE 3: Sketch of the structured mesh: (a) volute; (b) impeller.

TABLE 3: Boundary conditions.

\begin{tabular}{lcc}
\hline Location & Boundary condition types & Settings \\
\hline Inlet & Mass flow inlet & $101,325 \mathrm{~Pa}$, turbulence intensity \\
Outlet & Pressure outlet & Equal to the operating flow rate \\
Wall & Nonslip wall & Surface roughness $0.005 \mathrm{~mm}$ \\
Impellers & Rotating & $1485 \mathrm{r} / \mathrm{min}$ \\
Volute & Stationary & $0 \mathrm{r} / \mathrm{min}$ \\
Lateral cavity & Stationary & $0 \mathrm{r} / \mathrm{min}$ \\
\hline
\end{tabular}

TABLE 4: Numerical results with different turbulence models at $Q_{\text {des }}$.

\begin{tabular}{lcccccc}
\hline Turbulence model & Standard $k-\varepsilon$ & RNG $k-\varepsilon$ & Realizable $k-\varepsilon$ & Standard $k-\omega$ & SST $k-\omega$ & Test data \\
\hline Efficiency $\eta(\%)$ & 46.34 & 48.22 & 47.48 & 46.45 & 48.51 \\
$H(\mathrm{~m})$ & 23.54 & 24.64 & 24.16 & 23.74 & 24.89 & 20.24 \\
\hline
\end{tabular}

TABLE 5: Orthogonal experimental factors.

\begin{tabular}{lcccc}
\hline Level & $D_{2}(\mathrm{~mm})$ & $b(\mathrm{~mm})$ & $\beta_{2}\left({ }^{\circ}\right)$ & $\beta_{1}\left(^{\circ}\right)$ \\
\hline 1 & 340 & 70 & 35 & 60 \\
2 & 350 & 60 & 40 & 50 \\
3 & 360 & 50 & 45 & 40 \\
\hline
\end{tabular}

TABLE 6: Test arrangements and scheme.

\begin{tabular}{lcccccc}
\hline Test serial number & A & B & C & D & Efficiency $\eta(\%)$ & $H(\mathrm{~m})$ \\
\hline 1 & 1 & 1 & 1 & 1 & 49.06 & 30.58 \\
2 & 1 & 2 & 2 & 2 & 48.95 & 29.12 \\
3 & 1 & 3 & 3 & 3 & 48.06 & 25.92 \\
4 & 2 & 1 & 2 & 3 & 50.58 & 33.38 \\
5 & 2 & 2 & 3 & 1 & 50.16 & 33.04 \\
6 & 2 & 3 & 1 & 2 & 47.69 & 27.91 \\
7 & 3 & 1 & 3 & 2 & 49.80 & 34.85 \\
8 & 3 & 2 & 1 & 3 & 49.86 & 31.25 \\
9 & 3 & 3 & 2 & 1 & 47.20 & 29.52 \\
\hline
\end{tabular}

ranges are the most important factors; they are the most influential factors of indicators. The results show that $\mathrm{B}, \mathrm{A}$, $\mathrm{D}$, and $\mathrm{C}$ are the major-minor sequences among factors influencing efficiency, and $\mathrm{B}, \mathrm{A}, \mathrm{C}$, and $\mathrm{D}$ represent the major-minor sequences among factors on influencing head. $\mathrm{A}_{2} \mathrm{~B}_{1} \mathrm{C}_{1} \mathrm{D}_{3}$ represents the optimum level obtained from single index analysis of efficiency, and $A_{3} B_{1} C_{3} D_{1}$ signifies the optimum level obtained from single index analysis of heads.

In general, when analyzing the influence of factors on assessment indicators, if it is a single factor, combination of the best factors is considered the best production condition when interaction of factors cannot be considered. However, this paper considered two indicators, which belonged to multi-index orthogonal experiment. The factors not only consider efficiency and head of primary and secondary indicators separately but also consider ultimate goals of primary and secondary factors according to pump performance. 
TABle 7: Variance analysis of efficiency and head.

\begin{tabular}{lcccccccc}
\hline & \multicolumn{4}{c}{ Efficiency $\eta(\%)$} & & \multicolumn{2}{c}{$H(\mathrm{~m})$} & \\
& $\mathrm{A}$ & $\mathrm{B}$ & $\mathrm{C}$ & $\mathrm{D}$ & $\mathrm{A}$ & $\mathrm{B}$ & $\mathrm{C}$ \\
\hline$K_{1}$ & 146.070 & 149.439 & 146.610 & 146.421 & 85.620 & 98.811 & 89.739 \\
$K_{2}$ & 148.431 & 148.971 & 146.730 & 146.439 & 94.329 & 93.411 & 92.019 \\
$K_{3}$ & 146.859 & 142.950 & 148.250 & 148.500 & 95.619 & 83.349 & 93.810 & 91.881 \\
$k_{1}$ & 48.690 & 49.813 & 48.870 & 48.807 & 28.540 & 32.937 & 29.913 & 31.047 \\
$k_{2}$ & 49.477 & 49.657 & 48.910 & 48.813 & 31.443 & 31.137 & 30.673 \\
$k_{3}$ & 48.953 & 47.650 & 49.340 & 49.500 & 31.873 & 27.783 & 31.270 \\
$R$ & 0.787 & 2.163 & 0.470 & 0.693 & 3.333 & 5.154 & 30.627 \\
\hline
\end{tabular}

The aim of this orthogonal test is to improve the efficiency and reach the specified head at the same time and also take into account the passing performance of the vortex pump. Therefore, the best combination of $\mathrm{A}_{2} \mathrm{~B}_{2} \mathrm{C}_{3} \mathrm{D}_{3}$ was obtained by comprehensive analysis of the various factors with $D_{2}=350 \mathrm{~mm}, b=60, \beta_{2}=45^{\circ}$, and $\beta_{1}=60^{\circ}$. Two-dimensional hydraulic design of impeller is carried out by using the optimal combination parameters. Then, 3D modeling, meshing, and numerical simulation are performed, and the efficiency and head value of the optimal scheme are obtained. The optimum program presented efficiency and head values of $51.02 \%$ and $32.03 \mathrm{~m}$. The purpose of optimization design was achieved by comparing nine schemes of simulation results as shown in Table 6. The efficiency and head value of the optimal scheme pump are much higher than the original scheme pump.

3.2. Pump Performance Verification. Based on the two-dimensional hydraulic design drawing of the optimal impeller, the prototype was trial-produced, and the experimental research and verification were conducted.

Figure 4 shows prototype pump and optimization pump impeller. Optimization pump was tested by test rig, as shown in Figure 5. Experiments were conducted in an open-type pump system, with identification coming from Jiangsu Province of China [2]. Test rig comprises two parts, namely, data acquisition system and water circulation system $[27,28]$. Data acquisition system changes all kinds of physical quantities at different conditions, whereas water circulation system supplies the necessary environment for vortex pumps. The test rig is shown in Figure 5.

Test facilities and measurement methods abide by measurement requirements described in [29]. A turbine flow meter was used to measure flow $Q$, and the precision of turbine flow meter was $\pm 0.3 \%$. Speed $n$ was measured by a tachometer. The pump outlet pressure was measured using a pressure transmitter with $0.1 \%$ measurement error [30]; the expanded uncertainty of efficiency was $0.5 \%$.

In the pump performance test, pump efficiency is defined as follows [16]:

$$
\eta=\frac{\rho g Q H}{P_{S}} \times 100 \%,
$$

where $\eta$ is the pump efficiency, $Q$ represents the flow $\left(\mathrm{m}^{3} / \mathrm{s}\right)$, $H$ is the pump head (m), and $P_{s}$ is the output power of motor (W).

$$
H=\frac{\left(P_{\text {out }}-P_{\text {in }}\right)}{\rho g},
$$

where $P_{\text {in }}$ is the inlet total pressure, and $P_{\text {out }}$ is the outlet total pressure (unit of measuring $P_{\text {in }}$ and $P_{\text {out }}$ is $\mathrm{Pa}$ ).

The comparison between the numerical and experimental results of the optimization model performance is shown in Figure 6. The numerical simulation yielded efficiency and head values that were higher than the experimental values, because volume loss and mechanical loss cannot be considered in tests. The numerical results were consistent with the experimental results, which also proved the feasibility of numerical simulation.

The comparison between the test results of the optimized model and prototype model is shown in Figure 7. The efficiency and head measured $46.92 \%$ and $29.36 \mathrm{~m}$, respectively. Vortex pump efficiency was relatively low because the centrifugal and swirl forces produced by the rotating impeller caused a through flow and circulation flow, resulting in a significant hydraulic loss. In general, efficiency of vortex pump was $50 \%$. Pump efficiency decreased evidently [27] when $n_{\mathrm{s}}>130$ and $n_{\mathrm{s}}<60 . n_{\mathrm{s}}$ of the studied pump was 166 , indicating low efficiency. However, efficiency value of the best efficiency point (BEP) was still 5.07\% higher than the efficiency value of prototype pump. Head value of BEP was approximately $9 \mathrm{~m}$ higher than that of the prototype pump. Efficiency and head values were significantly improved and therefore met the design requirements.

\subsection{Internal Flow Field Analysis}

3.3.1. Characteristics of Inlet Rotating Reflux. Figure 8 shows the flow pattern analysis of the inlet pipe section of the numerical simulation of the vortex pump. It can be seen from the figure that part of the liquid flows back from the pump cavity to the inlet section, and the rotation direction of the reflux is consistent with that of the impeller. In this way, it enters into the inlet section in the form of a spiral from the lateral cavity, adheres to the wall of the inlet pipe, and continuously mixes with the inlet flow, resulting in the gradual weakening of the reflux kinetic energy, and finally reaches a balance with the inlet flow at a certain position. The spiral reflux in the inlet pipe is due to the special lateral cavity of the vortex pump, which has a strong circulation flow in the lateral cavity, which forms the reflux. This reflux leads to a large energy loss. Through the comparison of inlet flow patterns under three different working conditions in 


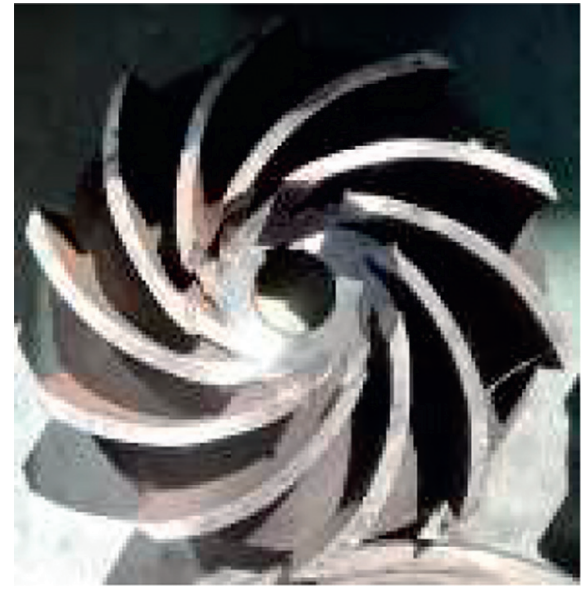

(a)

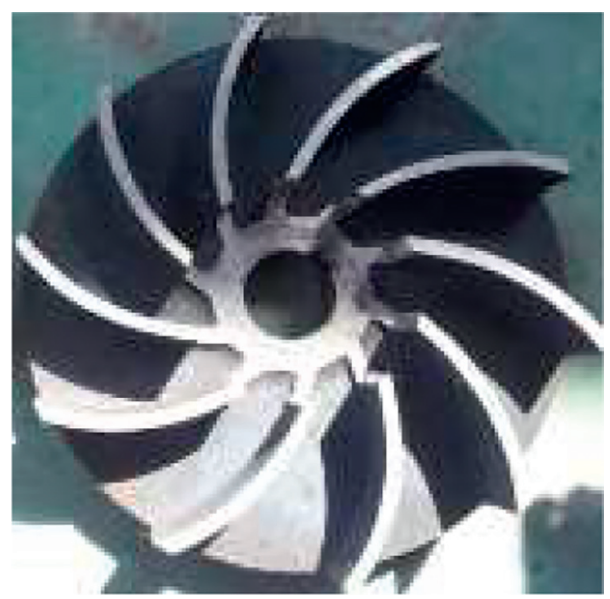

(b)

FIGURE 4: The pump impeller in the original model and optimization model: (a) prototype impeller; (b) optimization impeller.

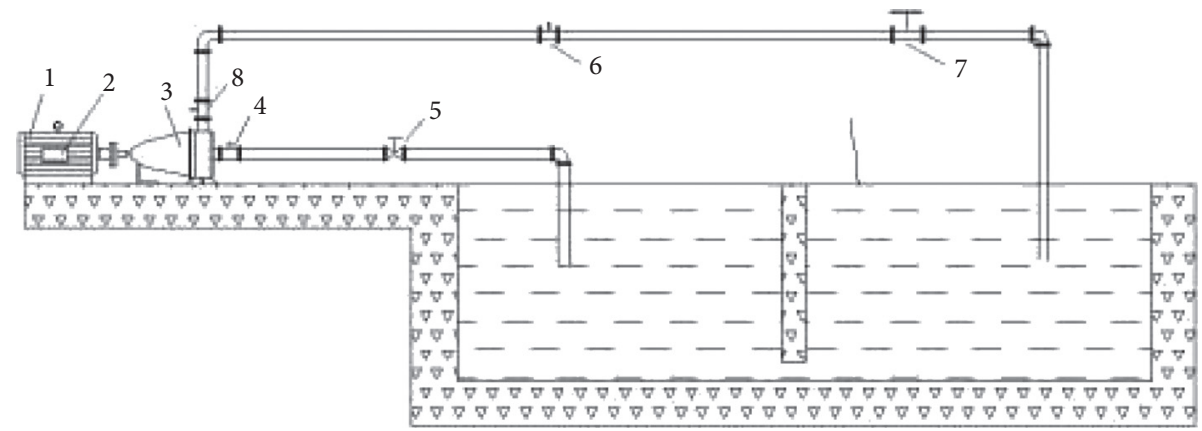

Figure 5: Experimental system. (1) Motor; (2) rotational speed meter; (3) test pump; (4) inlet pressure sensor; (5) inlet valve; (6) turbine flow meter; (7) outlet valve; (8) outlet pressure sensor.

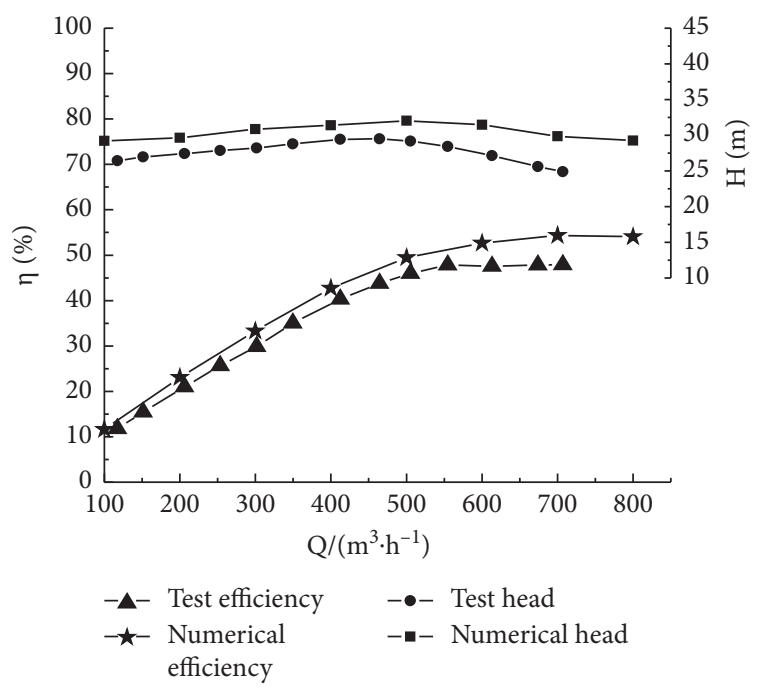

Figure 6: Comparison between the numerical and experimental results of the optimization model performance.

Figure 8 , it can be clearly seen that, under the small flow rate condition, the rotating reflux is strong, and the rotating reflux length is far away from the pump cavity, while, under

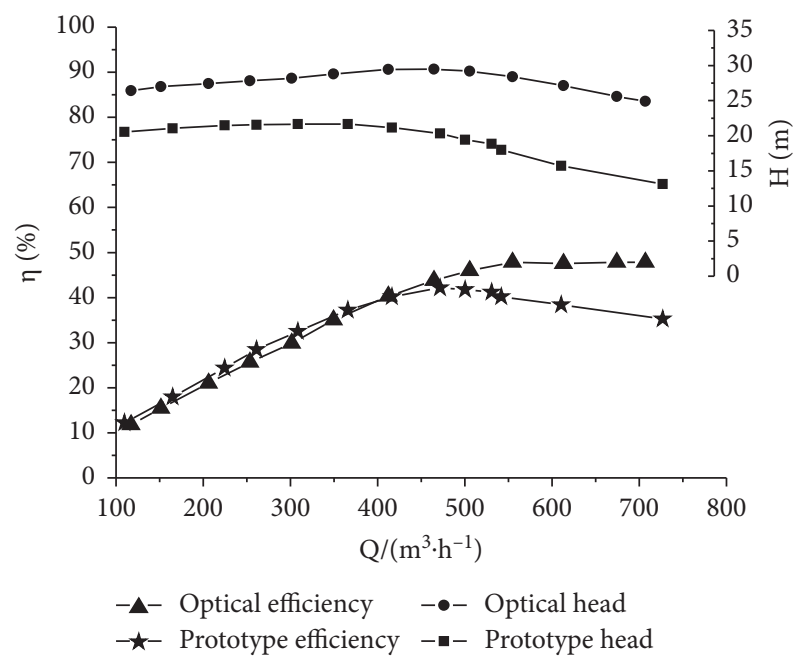

Figure 7: Comparison between the test results of the optimized model and prototype model.

the large flow rate condition, the reflux balance position moves to the pump cavity. This is mainly because, under the condition of a large flow rate, the inlet velocity is larger and the kinetic energy is stronger. When the impeller speed is 


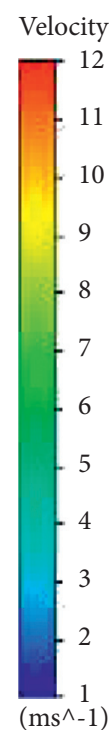

Velocity

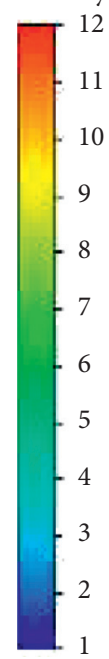

$\left(\mathrm{ms}^{\wedge}-1\right)$

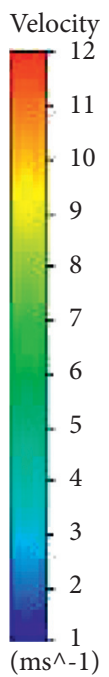

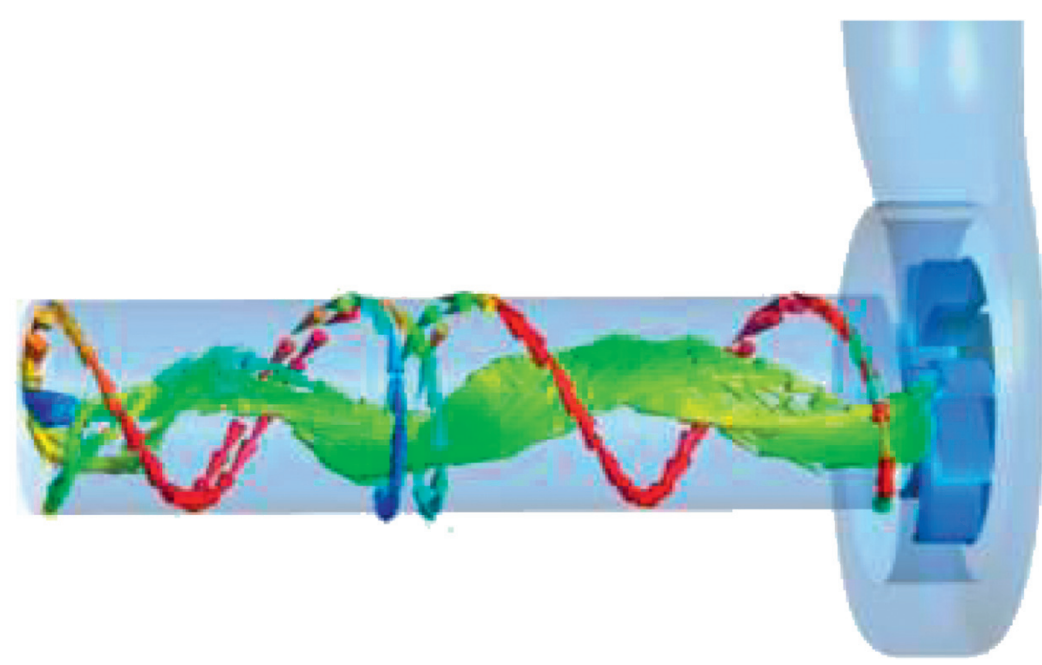

(a)

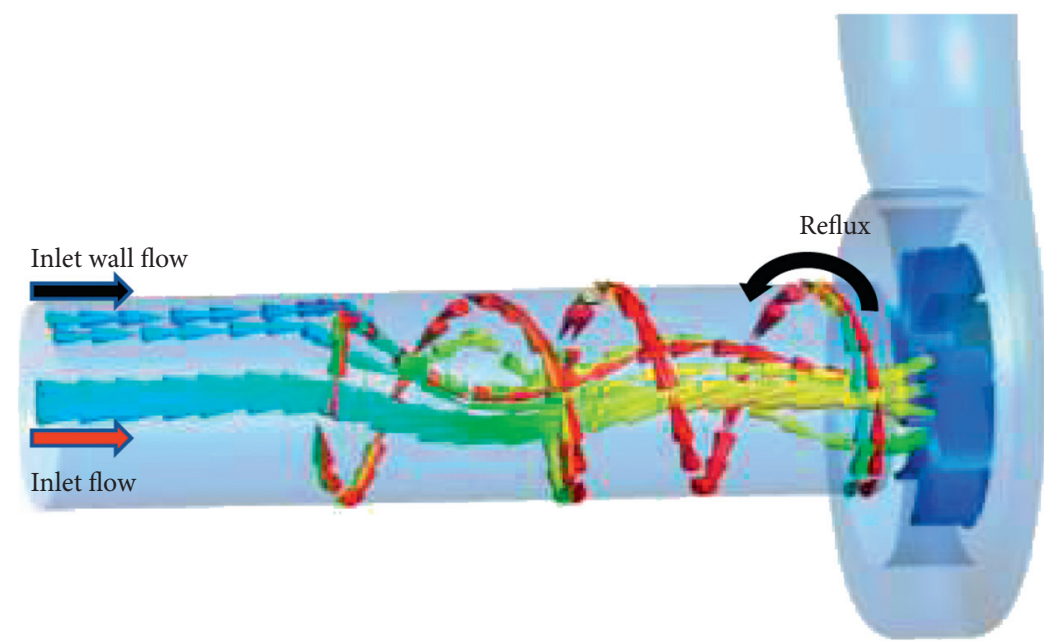

(b)



(c)

FIGURE 8: Swirl phenomenon in the inlet section of open-design vortex pump. (a) 0.6Qdes working condition, (b) 1.0Qdes working condition, and (c) 1.4 Qdes working condition. 


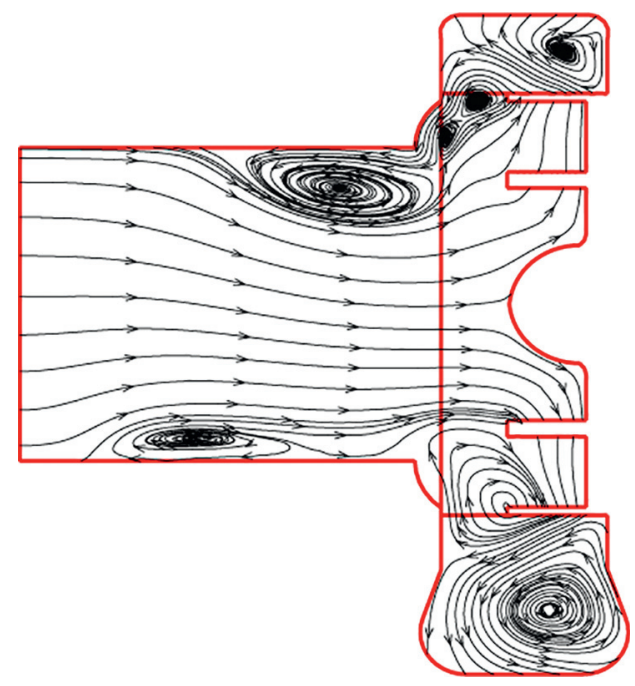

(a)

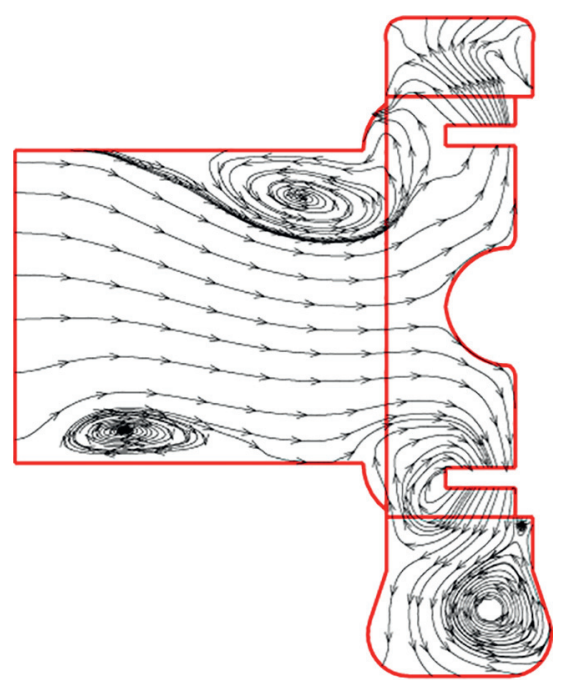

(b)

FIGURE 9: Streamline in a middle section: (a) prototype model; (b) optimization model.

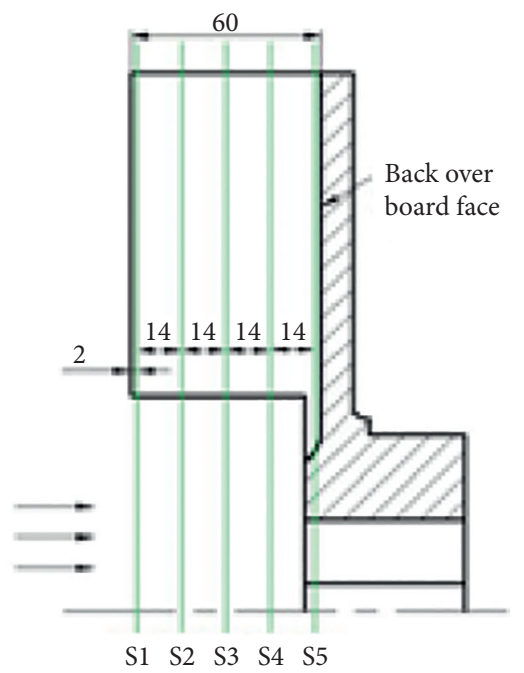

(a)

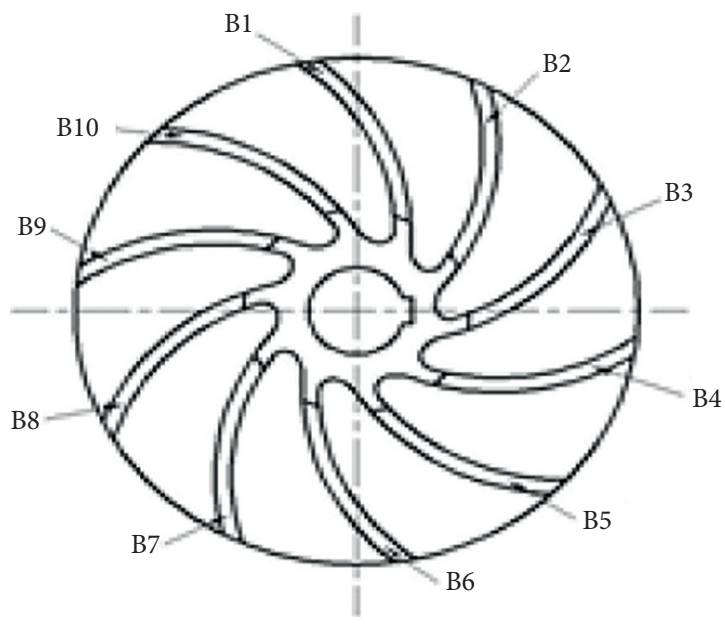

(b)

Figure 10: A sketch of the impeller: (a) cross-sectional position; (b) blade code.

constant, the backflow intensity in the lateral cavity does not change, and the reflux strength entering the inlet is unchanged, so the rotating reflux length is close to the pump cavity under a large flow rate.

Figure 9 shows pump middle section streamline of prototype and optimal pump at rated flow conditions. Two different degrees of reflux phenomena exist. The loss was smaller in distant areas from the impeller, whereas the loss was larger near the cavity, where more significant influence was noted in the impeller inflow. The prototype pump exhibited a large recirculation zone between lateral cavity and pump inlet; refluxes between impeller outlet and volute inlet were also observed. Less reflux regions and less internal losses were noted in optimized pump model compared with prototype pump. Thus, the optimized pump demonstrated a better flow state than the prototype.
3.3.2. Analysis of Flow Line and Pressure Field in Impeller. The flow field of impeller channel is significant to the special structure open-design vortex pump. The impeller channel of the optimized pump will be used to analyze the flow field characteristics. The cross-sectional position of the impeller and the blade number schematic is shown in Figure 10. "S" represents impeller cross-section, and " $B$ " represents the blade of the impeller.

Figure 11 shows pressure $(\mathrm{Pa})$ and relative velocity vectors in the average cross-sectional plane of the impeller at rated condition. As shown in S1, static pressure gradually increases from import to export inside the impeller. Static pressure of suction face B2-B5 is lower than those of other blades. The lowest static pressure is observed between B3 and B4. The largest vortex flow occurs between B8 and B9. Both sides of the blade 


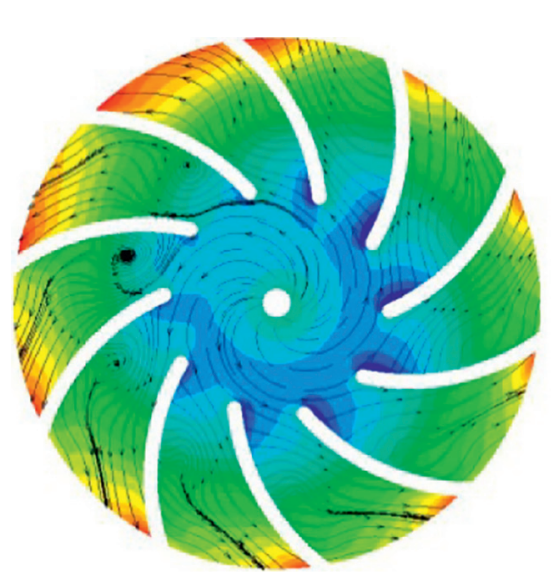

(a)

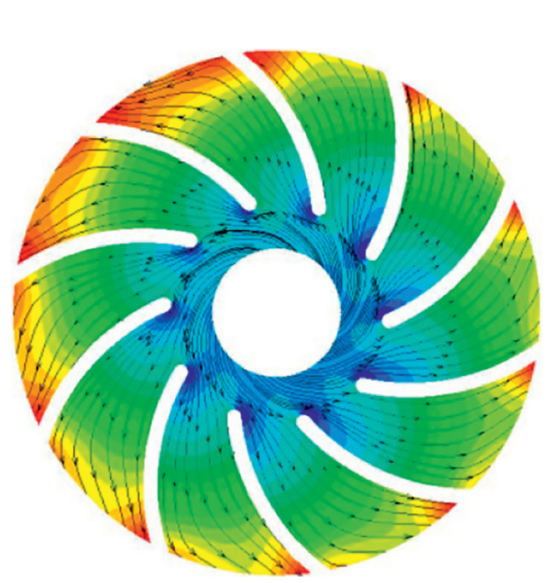

(c)

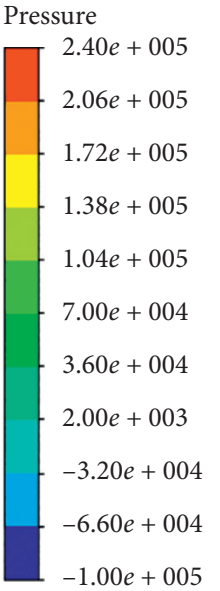

$(\mathrm{Pa})$

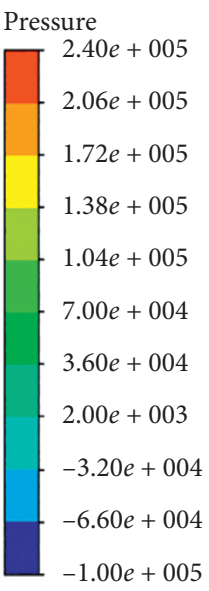

(Pa)

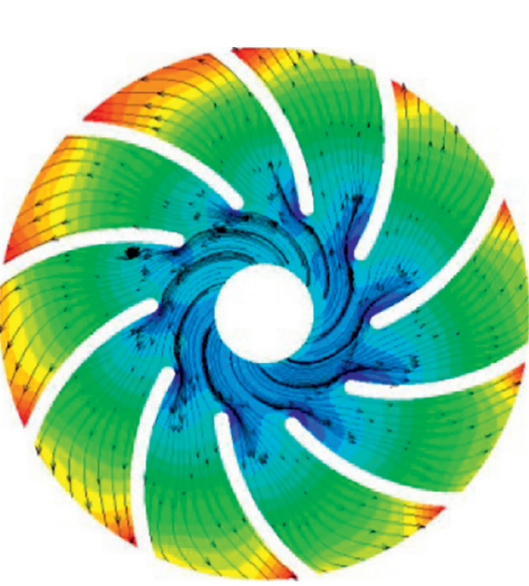

(b)

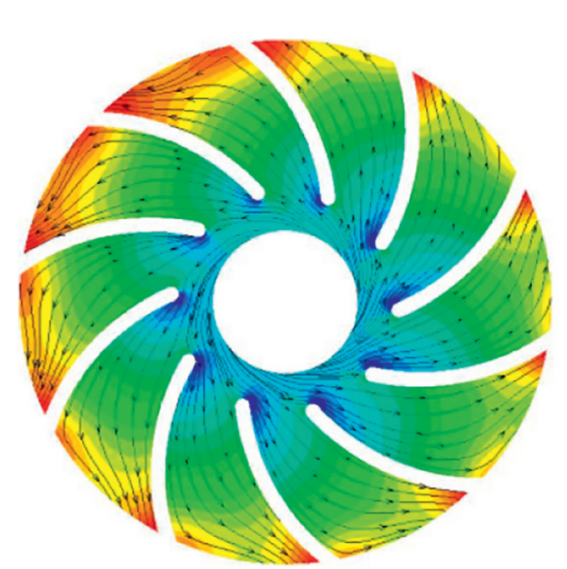

(d)

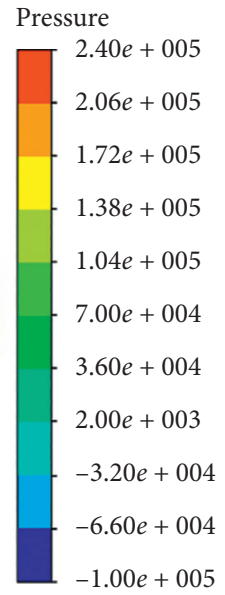

$(\mathrm{Pa})$

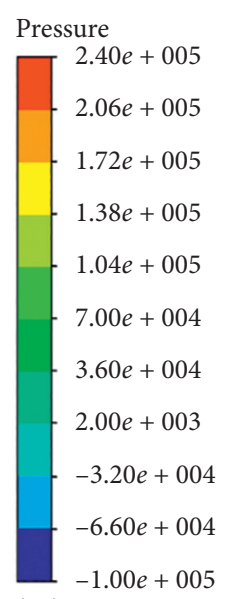

$(\mathrm{Pa})$

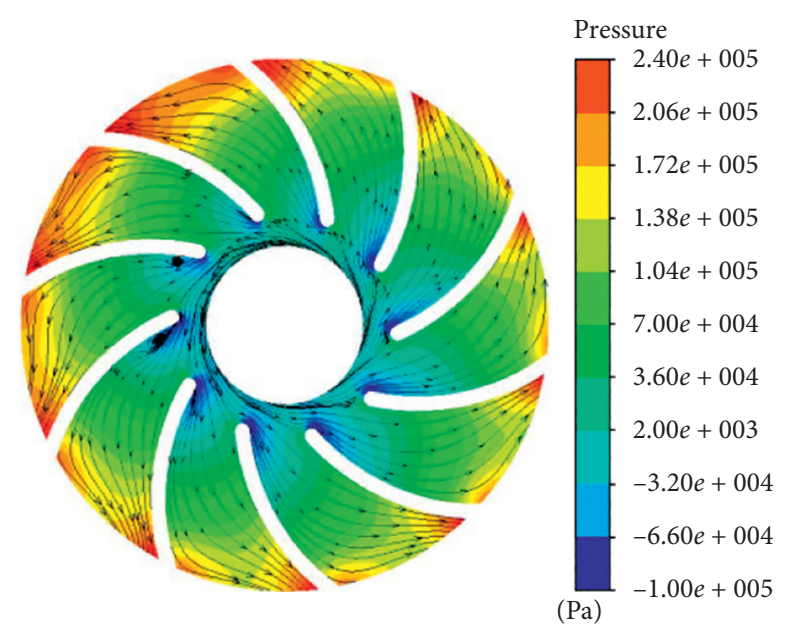

(e)

FIgURE 11: Pressure (Pa) and relative velocity vectors in the average cross-sectional plane of the impeller: (a) S1; (b) S2; (c) S3; (d) S4; (e) S5.

exhibited reduced vortex strength. This vortex mainly occurs at the suction face near the blade entrance. However, only part of the blade operates at the vortex. The main reasons are as follows: (1) the flow field under the influence of volute tongue was coupled with the vortex volute for nonsymmetry; B7-B9 channels represent highpressure volute areas; (2) from the cross-section to the front end of the blade, the distance is only $2 \mathrm{~mm}$, and the 
impeller is without a cover board; liquid flows from the front face to the back of the blade and to the direction of inlet. Liquid flow joins the flow through the blade inlet, causing a generation of the vortex flow.

With the blade flow field in the back cover, the liquid mainly comes from the inlet edge of the blade and across the blade of front face. After the rotation of the impeller, the liquid comes out from the front face of blade outlet and exhibits no influence on the inside channel of the impeller blade. S2-S5 illustrations clearly demonstrate this process. However, the suction face of the impeller inlet is assumed to appear in different degrees of backflow phenomenon in channel 8 of S2 and channels 7 and 8 of S5. This phenomenon differs from that of S1 in the backflow phenomenon. Vortex flow appears in S1 because of the broad volute of pump chamber in vortex pumps. Vortex flow was observed in S2 and S5 images; such an appearance is similar to that of the ordinary centrifugal pumps. Inlet setting angle of blade is due to the backflow in the suction face of the impeller inlet.

\section{Conclusions}

In this paper, a type of open-design vortex pump has been optimally designed and experimentally verified, and the optimized model pump has been numerically simulated under different flow conditions. Through numerical simulation and experiments, performance curves and internal flow field results have been obtained. The conclusions include the following aspects.

(1) An optimization scheme was obtained for the orthogonal experiment method. The experimental results showed that efficiency and head of optimized pump were $4.2 \%$ and $9 \mathrm{~m}$ higher than those of the prototype model pump, respectively, and the numerical calculation results of the optimization scheme pump are in good agreement with the test results.

(2) Due to the special open-design vortex pump structure, there is a broad lateral cavity, resulting in part of the liquid flowing back from the pump cavity to the inlet section. The rotation direction of the reflux is consistent with that of the impeller, and it enters into the inlet section in the form of spiral from the lateral cavity. Under the small flow rate condition, the rotating reflux is strong, and the rotating reflux is far away from the pump cavity, and the rotating reflux length $(L)$ decreases with the increase of the flow rate condition.

(3) In the open-design vortex pump front end of impeller and lateral cavity junction area, the fluid flows into the impeller from the lateral cavity and then flows out from the back half area of impeller to the lateral cavity, and the fluid in the lateral cavity flows back to the impeller channel from the whole suction face. The results of this study can provide a reference for the impeller design and engineering application.

\section{Abbreviations}

$D_{2}:$ Impeller outer diameter;

$b_{2}$ : Width of blade;

$\beta_{1}$ : Impeller inlet blade angle;

$\beta_{2}$ : Impeller outlet blade angle;

Q: Flow rate;

$H$ : Head;

$n$ : Liquid density;

$n_{s}: \quad$ Specific speed;

L: $\quad$ Lateral cavity width;

$z$ : $\quad$ Number of blade;

$\eta$ : $\quad$ Pump efficiency;

$p_{\text {out }}$ : Total pressure at impeller outlet;

$p_{\text {in }}$ : Total pressure at impeller inlet;

$\rho: \quad$ Liquid density;

$g:$ Gravity acceleration;

Ps: Output power of motor.

\section{Data Availability}

The data used to support the findings of this study are included within the article.

\section{Conflicts of Interest}

The authors declare no conflicts of interest.

\section{Authors' Contributions}

X. G. and W. S. conceptualized the study and developed the methodology. R. Z. provided the software. R. Z. and W. S. performed validation. X. G. performed formal analysis, provided the resources, wrote the original draft, and is responsible for funding acquisition. $\mathrm{H}$. W. performed investigation. T. Z. performed data curation and visualization. W. S. and R. Z. reviewed and edited the article. W. S. is responsible for the supervision and project's administration. All authors have read and agreed to the published version of the manuscript.

\section{Acknowledgments}

This research was funded by the National Natural Science Foundation of China (grant nos. 51909108 and 51979138).

\section{References}

[1] O. Hideki, N. Yukitoshi, and S. Kazuaki, "A study on internal flow and performance of a vortex pump: part 1 theoretical analysis," Bulletin of the JSME, vol. 26, no. 216, pp. 999-1006, 1983.

[2] X. Gao, T. Zhao, W. Shi et al., "Numerical investigation of an open-design vortex pump with different blade wrap angles of impeller," Processes, vol. 8, no. 12, p. 1601, 2020.

[3] G. P. Schivley and J. L. Dussourd, "An analytical and experimental study of a vortex pump," Journal of Basic Engineering, vol. 92, no. 4, pp. 889-900, 1970.

[4] H. Chen, "Measurement of rotating flow field with in the impeller of vortex pump," Transactions of the Chinese Society for Agricultural Machinery, vol. 27, pp. 49-54, 1996. 
[5] H. Quan, Y. Guo, Y. Yang, T. Cai, X. Chen, and X. Yu, "Effect of blade type on energy conversion of vortex pump," Transactions of Chinese Society of Agricultural Machinery, vol. 51, pp. 123-129, 2020.

[6] Y. Sha, Y. Zhu, P. Wu, Q. Li, Y. Wang, and C. Li, "Hydrotransport test with variable rapeseed concentration and flow field numerical simulation of vortex pump," Transactions of Chinese Society of Agricultural Machinery, vol. 50, pp. 173180, 2019.

[7] S. Alexander, W. Hendrik, and O. Alfred, "Numerical and experimental investigations of the unsteady cavitating flow in a vortex pump," Journal of Hydrodynamics, vol. 22, no. 5 Supplement 1, pp. 324-329, 2010.

[8] G. Peng, G. Zhou, Z. Hu, and H. Zhou, "Influence of back blade on wear of heavy slurry pump under low flow condition," Journal of Drainage and Irrigation Machinery Engineering, vol. 38, pp. 332-338, 2020.

[9] L. Wang, H. Liu, K. Wang, L. Zhou, X. Jiang, and Y. Li, "Numerical Simulation of the sound field of a five-stage centrifugal pump with different turbulence models," Water, vol. 11, no. 9, p. 1777, 2019.

[10] Y. Wang, R. Hu, H. Tang, Q. Wang, H. Yu, and J. Jia, "Flowinduced noise of self-priming vortex pump at low-flow rate," Transactions of Chinese Society of Agricultural Machinery, vol. 48, pp. 188-195, 2017.

[11] K. Liu, C. Wang, Y. Feng, and B. Hu, "PIV measurements and CFD computations of internal flow characteristics of rotational flow self-priming pump," Journal of Drainage and Irrigation Machinery Engineering, vol. 37, pp. 1025-1030, 2019.

[12] S. Gopalakrishnan, "Pump research and development: past, present, and future-an American perspective," Journal of Fluids Engineering, vol. 121, no. 2, pp. 237-247, 1999.

[13] L. Shi, J. Zhu, F. Tang, and C. Wang, "Multi-disciplinary optimization design of axial-flow pump impellers based on the approximation model," Energies, vol. 13, no. 4, p. 779, 2020.

[14] P. H. Hergt, "Pump research and development: past, present, and future," Journal of Fluids Engineering, vol. 121, no. 2, pp. 248-253, 1999.

[15] L. Zhou, W. Shi, W. Lu, B. Hu, and S. Wu, "Numerical investigations and performance experiments of a deep-well centrifugal pump with different diffusers," ASME, Journal of Fluids Engineering, vol. 134, no. 7, p. 071102, 2012.

[16] W. Shi, Y. Hou, L. Zhou, Y. Li, and S. Xue, "Numerical simulation and test of performance of deep-well centrifugal pumps with different stages," Journal of Drainage and Irrigation Machinery Engineering, vol. 37, pp. 562-567, 2019.

[17] W. Li, E. Li, L. Ji, L. Zhou, W. Shi, and Y. Zhu, "Mechanism and propagation characteristics of rotating stall in a mixedflow pump," Renewable Energy, vol. 153, pp. 74-92, 2020.

[18] Fluent Inc, Fluent User's Guide, Fluent Inc, USA, 2003.

[19] F. Wang, Computational Fluid Dynamics Analysis-CFD Principles and Application, pp. 144-158, Tsinghua University Press, Beijing, China, 2004.

[20] W. Zhao, Y. Zheng, Y. Liu, and X. Han, "The numerical analysis of the influence of sand volume fraction on the wear characteristics of centrifugal pumps," Journal of Drainage and Irrigation Machinery Engineering, vol. 2, pp. 98-103, 2018.

[21] J. F. Gulich, "Numerical flow calculations," in Centrifugal Pumps, pp. 439-506, Springer, New York, NY, USA, 2007.

[22] J. González, J. Parrondo, C. Santolaria, and E. Blanco, "Steady and unsteady radial forces for a centrifugal pump with impeller to tongue gap variation," Journal of Fluids Engineering, vol. 128, no. 3, pp. 454-462, 2006.
[23] X. He, Y. Zhang, C. Wang et al., "Influence of critical wall roughness on the performance of double-channel sewage pump," Energies, vol. 13, no. 2, p. 464, 2020.

[24] I. B. Celik, U. Ghia, P. J. Roache, C. J. Freitas, H. Coleman, and P. E. Raad, "Procedure for estimation and reporting of uncertainty due to discretization in CFD applications," Journal of Fluids Engineering, Transactions of the ASME, vol. 130, no. 7, pp. 780011-780014, 2008.

[25] F. Lewis, F. R. S. Richardson and J. Arthur Gaunt, VIII. The deferred approach to the limit," Philosophical Transactions of the Royal Society of London, vol. 226, pp. 299-361, 1927.

[26] T. Jiang, "Design of orthogonal test scheme," in Orthogonal Experimental Design, A. Meng, Ed., pp. 20-36, Shandong Science and Technology Press, China, 1987.

[27] J. Li, R. Zhang, R. Guo, and R. Li, "Influence of blade camber profile on hydraulic performance of slurry pump and impeller wear characteristic," Journal of Drainage and Irrigation Machinery Engineering, vol. 38, no. 1, pp. 21-27, 2020.

[28] H. Benigni, H. Jaberg, H. Yeung, T. Salisbury, O. Berry, and T. Collins, "Numerical simulation of low specific speed American petroleum institute pumps in part-load operation and comparison with test rig results," ASME Journal of Fluids Engineering, vol. 134, no. 2, 2012.

[29] International Standardization Organization, ISO 9906 Rotodynamic Pump-Hydraulic Performance Acceptance TestsGrades 1 and 2, International Standardization Organization, Geneva, 1999.

[30] X. Guan, "Design of vortex pump," in Modern Pumps Theory and Design, pp. 412-420, China Astronautic Publishing House, China, 2010. 